\title{
Altered Procollagen mRNA Expression during the Progression of Avian Scleroderma
}

\author{
Michael J. Ausserlechner, Roswitha Sgonc, Hermann Dietrich, \\ and Georg Wick \\ Institute for General and Experimental Pathology, Medical School, \\ University of Innsbruck, Austria
}

\begin{abstract}
Background: Spontaneous animal models of human autoimmune diseases provide the means to study the very first pathogenetic events, which is not possible in their human counterparts. This is particularly true for connective tissue diseases in which clinical symptoms become manifest only after a long and still obscure course of immunologic, inflammatory, and fibrotic processes. University of California at Davis line 200 chickens (UCD-200) develop a hereditary scleroderma-like disease resembling the entire spectrum of human systemic sclerosis, such as early endothelial cell damage, severe lymphocytic infiltration, and accumulation of collagen in skin and internal organs.

Materials and Methods: In the present study, we investigated mRNA levels of $\alpha_{1}(\mathrm{I}), \alpha_{2}(\mathrm{I}), \alpha_{1}(\mathrm{II}), \alpha_{1}(\mathrm{III})$, $\alpha_{1}(\mathrm{VI}), \alpha_{2}(\mathrm{VI})$, and $\alpha_{3}(\mathrm{VI})$ procollagen and GAPDH using digoxigenin-labeled antisense probes in a nonradioactive ribonuclease protection assay (RPA). We analyzed tissue samples from comb, esophagus, heart, lung, and liver of UCD-200 chickens at different stages of the disease, and healthy UCD-058 chickens.
\end{abstract}

Results: During the early inflammatory stage of the disease, the ratios of procollagen types VI/I and types VI/III increased 7-fold in comb tissue, followed by a 3-fold elevation in type I procollagen transcripts in the late acute stage. In the chronic stage, $\alpha_{1}$ (III) procollagen message was increased 2-fold. Additionally, hybridization with the 180 bp $\alpha_{2}(\mathrm{I})$ antisense probe resulted in two bands of $180 \mathrm{bp}$ and $115 \mathrm{bp}$, respectively, in the RPA. The ratio of these two previously undescribed bands changes in the early stage of the disease both in comb and esophagus.

Conclusions: In an animal model with a spontaneous scleroderma-like disease we found a characteristic, sequential increase in type VI, type I, and type III procollagen transcripts, and we found evidence for the presence and altered ratio of two mRNA variants of $\alpha_{2}(\mathrm{I})$ procollagen, possibly caused by alternative splicing. Comparative analysis of $\alpha_{2}(\mathrm{I})$ procollagen variants in early stages of avian scleroderma and human SSc might provide answers to unresolved questions concerning the molecular basis for generalized fibrosis in scleroderma.

\section{INTRODUCTION}

Scleroderma is an enigmatic disease of unknown etiology in which fibrosis develops in the skin and internal organs in association with vascular insufficiency (1). The immune system seems to play a crucial role in the initiation and perpetu-

Address correspondence and reprint requests to: Dr. Georg Wick, Institute for General and Experimental Pathology, Medical School, University of Innsbruck, A-6020 Inns-

bruck, Austria. Phone: 0043-512-507-3100; Fax: 0043-512507-2867; e-mail: Georg.Wick@uibk.ac.at ation of this condition. Investigation into the etiology of autoaggression requires animal models in which autoimmunity is induced experimentally or develops spontaneously (2-4). There are only a few animal models of hereditary spontaneous scleroderma, such as the tight skin (TSK) mouse (5-7) and the University of California at Davis (UCD) line 200 chicken $(8,9)$. Whereas TSK mice lack important symptoms of human scleroderma, such as certain inflammatory and immunological features (5), UCD-200 
chickens show numerous phenotypic and immunopathologic similarities to the human disease, i.e., early endothelial cell damage, severe lymphocytic infiltration of skin and viscera, vascular occlusion, and fibrosis of skin and internal organs (10-13). Serologically, these birds express rheumatoid factors and antinuclear antibodies (ANA) reactive with histones and DNA, as well as anticardiolipin antibodies $(14,15)$.

One to two weeks after hatching, UCD-200 birds develop an inflammation characterized by erythema of the comb, followed by edema and necrosis within 24 to $48 \mathrm{hr}$ ("self-dubbing"). The chickens exhibit severe perivascular infiltration in the skin with mainly $\gamma / \delta^{+} / \mathrm{CD}^{+} / \mathrm{MHC}$ class II $^{-} \mathrm{T}$ lymphocytes in the papillary dermis, and $\alpha / \beta^{+} / \mathrm{CD}^{+} / \mathrm{MHC}$ class $\mathrm{II}^{+} \mathrm{T}$ cells in the deeper dermis and in subcutaneous tissue. The interactions of these lymphocytes or their mediators with fibroblasts may be crucial in the initial disease stages and could cause the subsequent fibrosis with accumulation of collagen types I, III, and VI in the afflicted tissues (12).

It is believed that the excess of collagen in SSc results from overproduction by fibroblasts rather than from decreased breakdown (16). In vitro studies on cultured fibroblasts from UCD200 chickens and human scleroderma patients revealed increased collagen production compared with normal healthy controls $(17,18)$. However, the persistently abnormal behavior of fibroblasts from scleroderma lesions may also be due to a specific fibroblast subpopulation that exhibits an abnormal phenotype and may cause the characteristic alterations of the connective tissue (19).

We are mainly interested in the investigation of interactions between endothelial cells, infiltrating mononuclear cells, and fibroblasts leading to excessive collagen deposition. Because patients without overt symptoms are generally not yet under clinical supervision, the study of the initial stages is not possible in human scleroderma. In contrast, the rapid progress of spontaneous autoimmune disease in UCD-200 chickens allows for sequential studies beginning at the very early disease phase immediately after hatching, when no clinical manifestations are present, through chronic fibrosis stage. To elucidate the dynamics of procollagen mRNA expression in the UCD-200 model, we analyzed the mRNA levels of procollagen $\alpha_{1}(\mathrm{I}), \alpha_{2}(\mathrm{I}), \alpha_{1}(\mathrm{II})$, $\alpha_{1}(\mathrm{III}), \alpha_{1}(\mathrm{VI}), \alpha_{2}(\mathrm{VI})$, and $\alpha_{3}(\mathrm{VI})$ in comb and internal organs at different disease stages using digoxigenin-labeled antisense probes in a nonra-

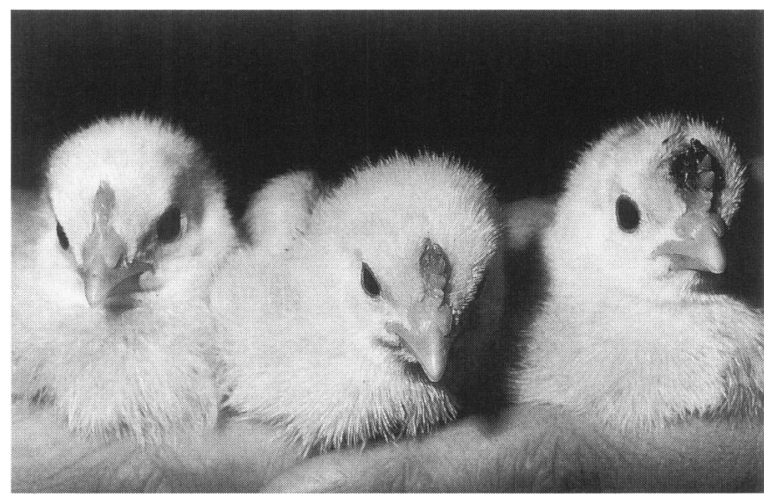

FIG. 1. Spontaneous inflammation in the comb of UCD-200 chickens

Eleven-day-old UCD-200 chickens in the acute phase of the disease exhibit the three stages of inflammation (from left): erythema $(1+)$, edema $(2+)$, and commencement of comb necrosis $(3+)$.

dioactive ribonuclease protection assay (RPA). The rapid and well-defined progress of avian scleroderma in UCD-200 chickens allowed us to investigate changes in procollagen mRNA patterns during the progression of this sclerodermalike disease.

\section{MATERIALS AND METHODS}

\section{Animals}

UCD-200 and healthy white Leghorn control line UCD-058 chickens were bred and maintained in the Central Laboratory Animal Facilities of the University of Innsbruck Medical School. The natural history and genetic characteristics of these UCD lines have been described previously $(8,20)$.

\section{Experimental Groups}

To observe the sequence of changes in the mRNA expression patterns, tissue samples were taken from 7-day-old UCD-200 chickens without clinical symptoms $(0)(n=5), 11$-day-old UCD-200 chickens in the acute phase of the disease showing the three consecutive stages of erythema $(1+)(n=5)$, edema $(2+)(n=5)$, and initial comb necrosis $(3+)(n=5)$ (Fig. 1) and from 33-day-old $(n=5)$ and 8-month-old $(n=5)$ animals in the chronic disease stage. Healthy UCD-058 chickens, 7 days $(n=5), 11$ days $(n=5), 33$ days $(n=5)$, and 8 months $(n=5)$ old, served as controls. The animals were sacri- 
TABLE 1. Subcloning of procollagen CDNA fragments

\begin{tabular}{lcc}
\hline cDNA & $\begin{array}{c}\text { Restriction } \\
\text { Sites Used for } \\
\text { Subcloning }\end{array}$ & $\begin{array}{c}\text { Length of } \\
\text { Subcloned } \\
\text { Fragment }\end{array}$ \\
\hline$\alpha_{1}(\mathrm{I})$ pCALl & PstI-HpaII & $250 \mathrm{bp}$ \\
$\alpha_{2}(\mathrm{I})$ pCAL3 & Bam HI-EcoRI & $180 \mathrm{bp}$ \\
$\alpha_{1}(\mathrm{II})$ pCAR 1 & PstI-BamHI & $310 \mathrm{bp}$ \\
$\alpha_{1}(\mathrm{III})$ pIN3 & EcoRI-BamHI & $190 \mathrm{bp}$ \\
$\alpha_{1}(\mathrm{VI})$ & PstI-BamHI & $410 \mathrm{bp}$ \\
$\alpha_{2}$ (VI) 4aU & EcoRI-PstI & $270 \mathrm{bp}$ \\
$\alpha_{3}(\mathrm{VI})$ & SacI-HindIII & $370 \mathrm{bp}$ \\
GAPDH pGAD28 & HindIII-PstI & $150 \mathrm{bp}$ \\
& & \\
\hline
\end{tabular}

For in vitro transcription, cDNA fragments were subcloned into the bacterial plasmid vector pGEM $4 \mathrm{Z}$ by using the above listed restriction enzymes.

ficed by cardiac puncture under sodium pentobarbital anesthesia; parts of comb, esophagus, heart, lung, and liver were removed and immediately frozen in liquid nitrogen.

\section{RNA Preparation}

Frozen tissue samples were homogenized in liquid nitrogen. Total RNA was prepared by Trisolv RNA Isolation Reagent (Biotecx, Houston, TX) according to the manufacturer's instructions. Contaminating DNA was digested with 20 units DNase (Boehringer Mannheim, Mannheim, Germany) at $37^{\circ} \mathrm{C}$ for $1 \mathrm{hr}$ and total RNA was isolated by a second purification step with Trisolv.

\section{Synthesis of Antisense RNA Probes}

cDNA clones of chicken procollagen $\alpha_{1}(\mathrm{I})$ pCALl (21), $\alpha_{2}(\mathrm{I})$ pCAL3 (21), $\alpha_{1}(\mathrm{II})$ pCARl (22), $\alpha_{1}(\mathrm{III})$ pIN3 (23), $\alpha_{1}(\mathrm{VI})$ (24), $\alpha_{2}(\mathrm{VI}) 4 \mathrm{aU}$ (25), $\alpha_{3}(\mathrm{VI})$ (26), and of chicken GAPDH pGAD28 (27) were shortened and subcloned into the bacterial plasmid vector pGEM4Z for digoxigenin11-UTP (Dig-UTP) labeling via in vitro transcription (Boehringer Mannheim) (Table 1). The quality of the antisense probes was tested in a nonradioactive RPA by using total RNA from chicken tissue, as a positive control to examine the size and specificity of the RNA probes, and yeast RNA as a negative control to exclude contaminations.

\section{Nonradioactive RPA}

Five micrograms total RNA from tissue samples (in comb tissue we used $2 \mu \mathrm{g}$ RNA) and mixtures of Dig-UTP-labeled antisense probes, $500 \mathrm{pg} / \mu \mathrm{l}$ respectively, were coprecipitated. Riboprobe set 1 consisted of antisense probes for procollagen types $\alpha_{1}(\mathrm{I}), \alpha_{2}(\mathrm{I}), \alpha_{1}(\mathrm{II}), \alpha_{1}(\mathrm{VI})$, and chicken GAPDH; riboprobe set 2 contained antisense probes for procollagen $\alpha_{1}(\mathrm{III}), \alpha_{2}(\mathrm{VI}), \alpha_{3}(\mathrm{VI})$, and GAPDH (Figs. 2A and 3A). The RPA was based on the RPA II Kit (Ambion, Austin, TX). Following hybridization at $52^{\circ} \mathrm{C}$, the formamide concentration in the RPA reaction mix was reduced to $11 \%$ and the mix was then incubated at $15^{\circ} \mathrm{C}$ for $30 \mathrm{~min}$ before RNase digestion of single-stranded RNA at $15^{\circ} \mathrm{C}$ for 30 min by RNase A/Tl. Protected RNA was separated on a $6 \%$ Tris-borate-EDTA (TBE) polyacrylamide gel and electroblotted onto a Hybond-N nylon membrane. Dig-UTPlabeled RNA was detected by chemiluminescence; exposed X-ray films (DuPont, Vienna, Austria) were analyzed by an Elscript 440 densitometer (Hirschmann, Taufkirchen, Germany). Because the signal strength is not linearly correlated to the amount of membrane-bound RNA, we calculated an exponential fitting curve to account for the nonlinear blackening of X-ray films (M. J. Ausserlechner et al., unpublished results). Since mononuclear infiltrations during the acute phase of the disease cause an increase in the amount of housekeeping gene transcript, we calculated ratios between different types of procollagen rather than referring to GAPDH. The signal intensities of bands representing specific procollagen transcripts were added and taken as $100 \%$.

\section{Statistical Analysis}

Differences between mean values were assessed for statistical significance by the Mann-WhitneyWilcoxon U test.

\section{RESULTS}

\section{Alterations of Procollagen mRNA Composition in the Acute Phase of the Disease in Comb and Internal Organs}

Aalysis of total RNA from comb tissue revealed interesting correlations between the different, visually assessible stages of inflammation and the molecular levels of collagen transcripts (Fig. 1). We found no differences in the abundance of specific procollagen transcripts between UCD-200 

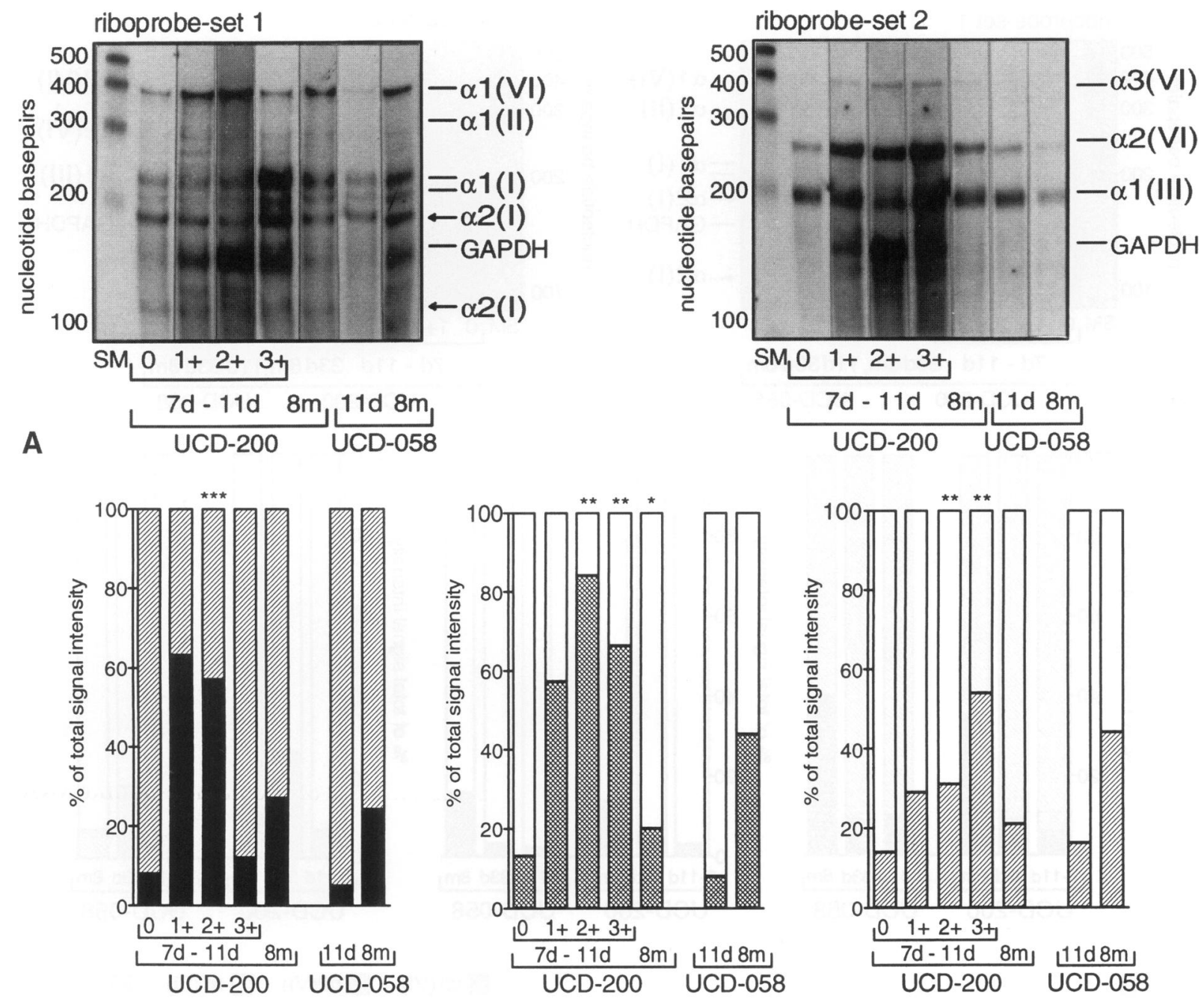

B

$\square \alpha 1(\mathrm{VI}) \times 2(\mathrm{VI}) \square \alpha 1(\mathrm{III}) \quad \square \alpha 1(\mathrm{I})$

FIG. 2. RPA of total RNA from comb tissue of UCD-200 and UCD-058 chickens

Two micrograms of RNA was hybridized with two sets of Dig-UTP-labeled probes (set 1: antisense probes for $\alpha_{1}(\mathrm{I})$, $\alpha_{2}(\mathrm{I}), \alpha_{1}(\mathrm{II})$ as a negative control, and $\alpha_{1}(\mathrm{VI})$ procollagen and GAPDH; set 2: antisense probes for $\alpha_{1}(\mathrm{III}), \alpha_{2}(\mathrm{VI})$, and $\alpha_{3}(\mathrm{VI})$ procollagen and GAPDH). Dig-UTP-labeled RNA was detected by chemiluminescence. Tissue samples were from UCD-200 without clinical symptoms $(0)$, erythema $(1+)$, edema $(2+)$, beginning necrosis $(3+)$ of the comb, and from the comb of 8-month-old (8m) UCD-200 chickens in the late chronic stage of the disease, as well as tissue samples from 11 -day-old (11d) and 8-month-old UCD-058 controls. (A) RPA blot: Ambion's Centurysize-marker (SM) was used to estimate band size. Arrows indicate the two mRNA variants of $\alpha_{2}(\mathrm{I})$ procollagen. In some lanes on the presented blots the lower $\alpha_{2}(\mathrm{I})$ and the $\alpha_{3}(\mathrm{VI})$ band are not visible since we had to find an exposure time that would show both strong bands and weak bands on the same blot. (B) Quantification: For densitometrical analysis, several films were exposed for each blot at varying times and used to calculate the relative signal abundancies and ratios of strong and weak bands via an exponential fitting curve to account for the nonlinear blackening of X-ray films. Signal intensities of the different procollagen transcripts were added and taken as $100 \%$. The UCD-200 groups were statistically compared with age-matched UCD-058 controls by using a Mann-WhitneyWilcoxon-U test; ${ }^{*} p<0.05 ;{ }^{* *} p<0.025 ;{ }^{* *} p<0.01$.

chickens without clinical symptoms (0) and UCD-058 controls of the same age. However, in UCD-200 chickens exhibiting comb erythema $(1+), \alpha_{1}(\mathrm{VI})$ and $\alpha_{2}(\mathrm{VI})$ procollagen transcripts were increased 7-fold and statistically significant elevations in edema $(2+)$ were observed compared with age-matched controls $(p<0.01, p<$ 0.025 ) (Fig. 2). In necrotic comb tissue, $\alpha_{2}(\mathrm{VI})$ mRNA was elevated 6-fold compared with agematched control animals $(p<0.025)$, and the 

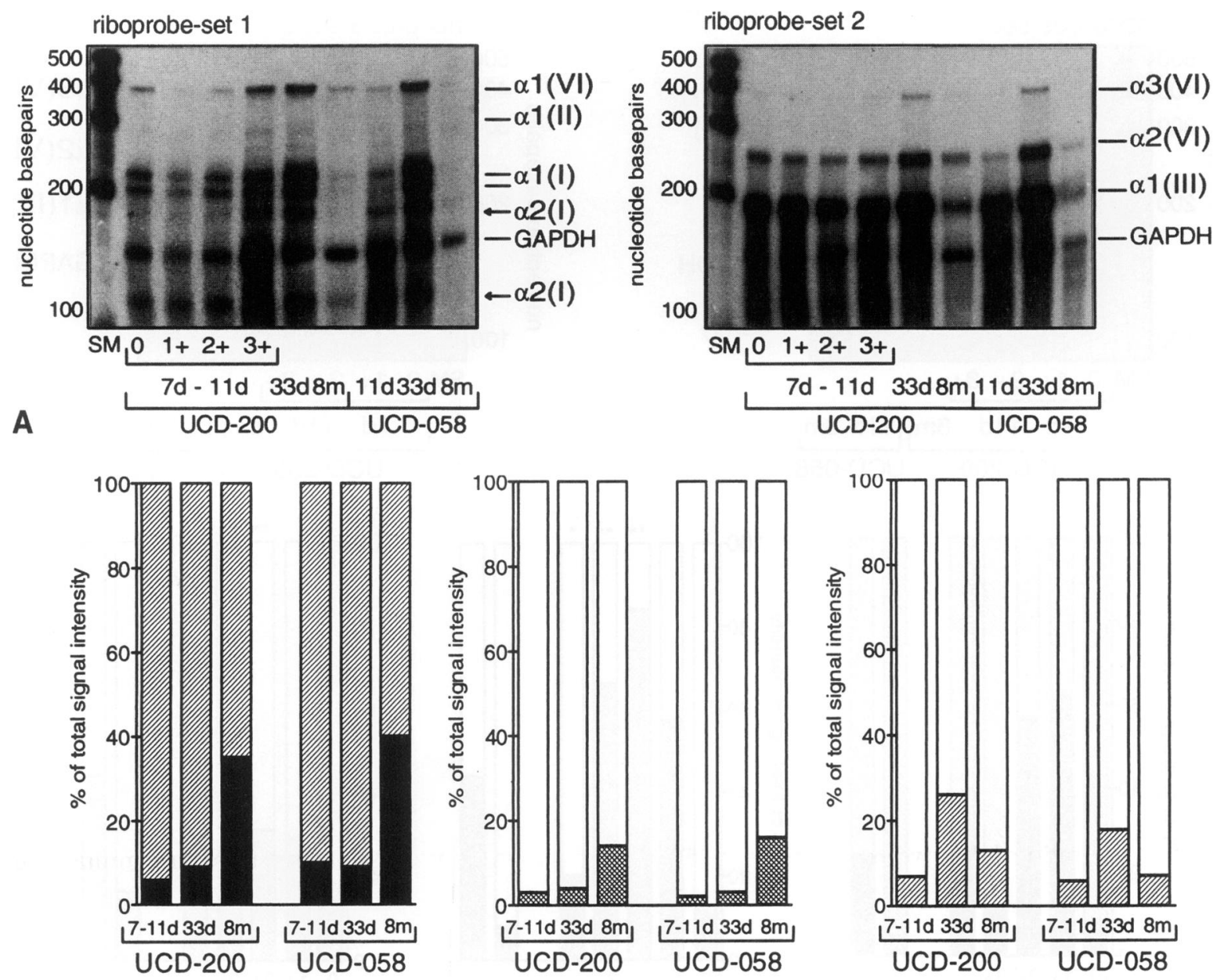

B

$\propto 1(\mathrm{VI}) \times 2(\mathrm{VI}) \square \alpha 1(\mathrm{III}) \quad \square \propto 1(\mathrm{I})$

\section{FIG. 3. Analysis of total RNA from esophagus}

Five micrograms of total RNA from esophagus tissue samples was analyzed using the same conditions, antisense probe combinations, and experimental groups as used for comb analysis, with the exception that 33-day-old (33d) UCD-200 and UCD-058 chickens were also examined. (A) RPA blot: Arrows indicate the two mRNA variants of $\alpha_{2}(\mathrm{I})$ procollagen. (B) Quantification: For statistical analysis of procollagen mRNA patterns in internal organs, material from 7- to 11-day-old (7-11d) UCD-200 chickens exhibiting different stages of comb involvement was pooled and compared with UCD-058 controls. Tissue samples from 33-day-old (33d) and 8-month-old (8m) UCD200 and UCD-058 chickens were also examined. No statistically significant differences were found between diseased chickens and healthy controls of the same age.

proportional amount of $\alpha_{1}(\mathrm{I})$ simultaneously rose 3 -fold $(p<0.025)$. Sclerotic tissue from the comb of birds in the chronic disease stage $(8$ months), which have no inflammatory infiltrates in the remaining tissues, still expressed a 1.5 -fold elevation in $\alpha_{1}$ (I) procollagen and a 2 -fold increase in $\alpha_{1}$ (III) procollagen message compared with age-matched UCD-058 controls $(p<0.01)$ (Fig. 2). In internal organs, the sequential, rapidly progressing differential elevation in various types of procollagen transcripts seen in comb tissue was not detectable at the investigated time points (Fig. 3). A characteristic age-dependent decrease in type I and III mRNA was found that is similar to that described in mammalian development (28).

\section{Hybridization Patterns of Antisense Probes in the RPA Suggest Different mRNA Variants of $\alpha_{1}(I)$ and $\alpha_{2}(I)$ Procollagen}

Another interesting finding of possible pathogenetic significance was that hybridization of the 


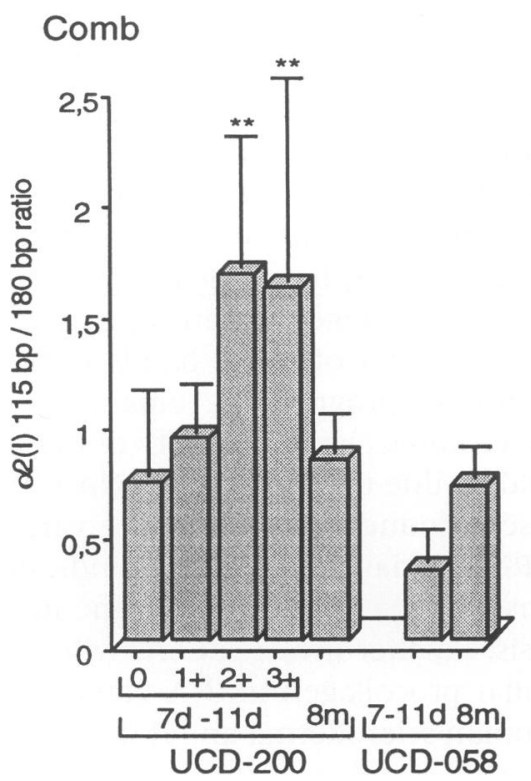

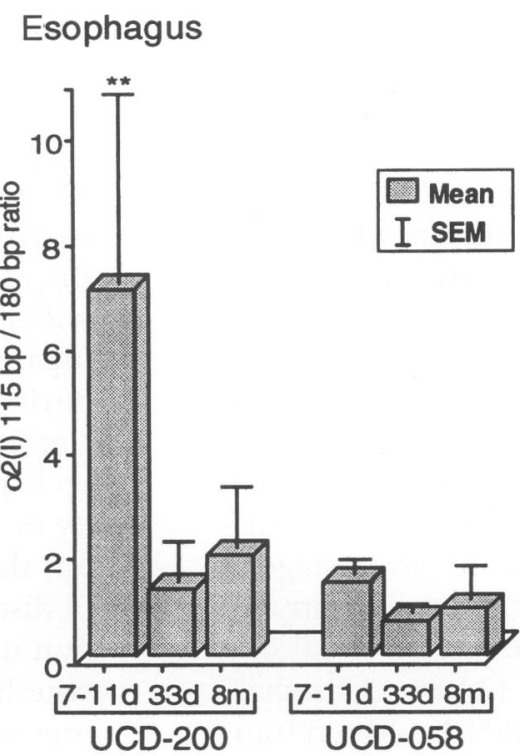

FIG. 4. Alteration of the $115 \mathrm{bp} / 180 \mathrm{bp}$ ratio during disease progression in comb and esophagus

Experimental groups are as described in Figures 2 and 3; differences between mean values were assessed for statistical significance by the Mann-Whitney-Wilcoxon U test; ${ }^{* *} p<0.025$.
$\alpha_{1}(\mathrm{I})$ antisense and the $\alpha_{2}(\mathrm{I})$ probes resulted in two bands, on the RPA blot in both diseased chickens and healthy controls (Figs. 2A and 3A). Whereas the ratio of the two $\alpha_{1}(\mathrm{I})$ bands at 250 bp (expected size) and at 210 bp was constant, that of the $\alpha_{2}$ (I) bands at $180 \mathrm{bp}$ (expected size) and $115 \mathrm{bp}$ (new) changed with the progression of avian scleroderma (Fig. 4). In comb tissue of UCD -200 chickens, the $115 \mathrm{bp} / 180 \mathrm{bp}$ band ratio increased 4 -fold at the early inflammatory phase of disease compared with controls $(p<0.025)$, as did the ratio $115 \mathrm{bp} / 180 \mathrm{bp}(p<0.025)$ in the esophagus of these birds. Three lung samples of both the 33-day-old and 8-month-old UCD-200 chickens were destroyed by RNase contaminations. In the two remaining lung tissue samples of 33-day-old UCD-200 birds we observed an up to 10 -fold increase in this ratio and a 3 -fold increase for 8-month-old birds. Unfortunately, it was impossible to detect the $115 \mathrm{bp}$ band in heart and liver, since the strong GAPDH signal caused an increased background below the GAPDH band (data not shown).

\section{DISCUSSION}

The investigations described here were designed to determine alterations in the procollagen mRNA patterns during the progression of avian scleroderma. The UCD-200 animal model, with its rapid and well-defined disease progress, made it possible to analyze the earliest stage of the disease before clinical symptoms become apparent, as well as the different phases of the acute stage and the involvement of internal organs. The use of nonradioactive RPA for simultaneous detection of procollagen transcripts allowed us to make clear assertions about changes in the expression patterns of the various transcripts. The high specificity of this test eliminated cross-hybridizations from antisense probes specific for the highly conserved 3'-propeptide regions of procollagen transcripts, and it allowed detection of type I procollagen mRNA variants.

Analysis of comb tissue revealed that the various visually determined stages of the acute phase were also reflected at the molecular level of procollagen transcripts. The data suggesting increased type VI procollagen mRNA during erythema and edema correspond well with reports on human scleroderma describing increased levels of type VI procollagen message in biopsies from patients in the acute phase of SSc (29). In vitro studies have shown that type VI collagen is mainly regulated by expression of the $\alpha_{3}(\mathrm{VI})$ chain, whereas the promotor of the $\alpha_{2}(\mathrm{VI})$ gene has some housekeeping gene characteristics $(30,31)$. We found strong $\alpha_{1}(\mathrm{VI})$ and $\alpha_{2}$ (VI) procollagen transcript signals but relatively weak $\alpha_{3}(\mathrm{VI})$ bands, indicating an excess of the first two transcripts, which corresponds nicely with the assumption that the amount of synthesized type VI collagen is regulated by a limiting $\alpha_{3}$ (VI) procollagen chain. However, the fact that all three $\alpha$-chain transcripts of type VI collagen are ele- 
vated in the same proportion could mean that an activated, strongly proliferating subpopulation of collagen-producing cells is partially responsible for fibrosis, as discussed for human SSc $(19,32)$.

In the late acute phase, when the comb tissue is destroyed by necrosis, the proportion of type I procollagen transcripts increases 3-fold and the absolute mRNA message is still 1.5 -fold elevated in old animals when mononuclear infiltrations have disappeared, which may explain the accumulation of type I collagen in avian scleroderma and human SSc $(8,33)$. Elevation in type III procollagen mRNA in skin tissue of UCD200 animals surviving the inflammatory stage of the disease is similar to that shown by in situ hybridization and at the protein level in skin tissue of chronic SSc patients $(34,35)$. This characteristic elevation in type I and III collagen transcripts has been described as induced in vitro by interleukin-1 (36).

In avian scleroderma, as in the human disease, those regions exposed to higher mechanical stress (comb, neck skin, toes) are afflicted first. Pathologic accumulation of collagen has been previously described in internal organs of 6month-old UCD-200 chickens, but not in younger animals (8). Visceral involvement obviously starts later, since the rapidly changing mRNA patterns found in inflamed comb tissue were not seen in internal organs at the investigated time points. The low survival rate of experimental animals precluded analysis of more groups in the chronic disease stage, making it impossible to detect the rapidly changing patterns seen in comb due to the large age gap between experimental groups. This is probably the reason why we detected only slightly increased levels of type I and III procollagen mRNA in 8-month-old UCD-200 chickens, since obviously, birds surviving to this age suffer from a milder, more slowly progressing fibrosis of internal organs.

The second finding, an unexpected hybridization pattern of antisense probes for $\alpha_{1}(\mathrm{I})$ and $\alpha_{2}(\mathrm{I})$ mRNA in the RPA, may be even more interesting. The two $\alpha_{2}(\mathrm{I})$ bands are observed both in UCD-200 and healthy UCD-058 chickens and were not detected in a common Northern blot. However, in an RPA, even small differences in the base sequence between antisense probe and mRNA are detectable (37). Since our antisense probes were specific for the 3 '-propeptide region of the $\alpha_{1}(\mathrm{I})$ and $\alpha_{2}(\mathrm{I})$ procollagen transcripts, we assumed that the reduced band size on the RPA blot was due to an alteration in the splicing site between the exons 51 and 52 of the $\alpha_{2}$ (I) procollagen transcripts that caused a mismatch between probe and the alternatively spliced mRNA in the RPA, which is digested by RNase treatment. Whereas the ratio of the two $\alpha_{1}$ (I) procollagen bands was relatively constant, the ratio of the two $\alpha_{2}(\mathrm{I})$ bands clearly correlated with different disease stages in comb and internal organs. Why the ratio of these bands changes during the disease progression remains to be clarified. The elevated signal intensity of the 115 bp band could be due to increased mRNA stability or increased production of this splice variant, but these mRNA variants may also be indicators of disease onset or may play a role in the initiation of fibrosis. Further investigations will show whether similar procollagen mRNA variants are present in human scleroderma and if they play a pathogenetic role in avian or human SSc.

\section{ACKNOWLEDGMENTS}

This study was supported by the Austrian Science Fund (G.W., project 10830), the LegerlotzFoundation (R.S.), and the Dr. Kolassa-Foundation for Rheumatologic Research (R.S.). cDNA clones pCAL1, pCAL3, pCARl were kindly provided by $\mathrm{E}$. Vuorio, Turku, pIN3 by W. Bertling, Erlangen, $\alpha_{1}(\mathrm{VI}), \alpha_{3}(\mathrm{VI})$ by A. Colombatti, Aviano, 4 aU by B. Trueb, Zürich, and pGAD28 by B. Auer, Innsbruck.

\section{REFERENCES}

1. Jayson MIV, Black CM (eds). (1988) Systemic Sclerosis: Scleroderma. John Wiley \& Sons, Chichester.

2. Cohen IR, Miller A (eds). (1994) Autoimmune Disease Models-A Guidebook. Academic Press, San Diego.

3. Wick G, Krömer G. (1992) Autoimmune disease, spontaneous experimental models. In: Roitt IM, Delves PJ (eds). Encyclopedia of Immunology. Academic Press, London, pp. 190195.

4. Wick G, Van De Water J, Gershwin ME. (1997) Avian models of autoimmunity. In: Lefkovits I (ed). Immunology Methods Manual: The Comprehensive Sourcebook of Techniques. Academic Press, San Diego, pp. 2269-2283.

5. Russel ML. (1983) The tight-skin mouse: Is it a model for scleroderma? J. Rheumatol. 10: 679-688. 
6. Jimenez SA, Williams CJ, Myers JC, Bashey RI. (1986) Increased collagen biosynthesis and increased expression of type I and type III procollagen genes in tight skin (TSK) mouse fibroblasts. J. Biol. Chem. 261: 657662 .

7. Bocchieri $\mathrm{MH}$, Henriksen PD, Kasturi $\mathrm{KN}$, Muryoi T, Bona CA, Jimenez SA. (1991) Evidence for autoimmunity in the tight skin mouse model of systemic sclerosis. Arthritis Rheum. 34: 599-605.

8. Gershwin ME, Abplanalp H, Casteles JJ, et al. (1981) Characterization of a spontaneous disease of white leghorn chickens resembling progressive systemic sclerosis (scleroderma). J. Exp. Med. 153: 1640-1659.

9. Van De Water J, Boyd R, Wick G, Gershwin ME. (1994) The immunologic and genetic basis of avian scleroderma, an inherited fibrotic disease of line 200 chickens. Int. Rev. Immunol. 11: 273-282.

10. Van De Water J, Gershwin ME, Abplanalp H, Wick G, von der Mark K. (1984) Serial observations and definition of mononuclear cell infiltrates in avian scleroderma, an inherited fibrotic disease of chickens. Arthritis Rheum. 27: 807-815.

11. Van De Water J, Haapanen L, Boyd R, Abplanalp H, Gershwin ME. (1989) Identification of $\mathrm{T}$ cells in early dermal lymphocytic infiltrates in avian scleroderma. Arthritis Rheum. 32: 1031-1040.

12. Gruschwitz MS, Moormann S, Kromer G, et al. (1991) Phenotypic analysis of skin infiltrates in comparison with peripheral blood lymphocytes, spleen cells and thymocytes in early avian scleroderma. J. Autoimmun. 4: 577-593.

13. Sgonc R, Gruschwitz MS, Dietrich H, Recheis H, Gershwin ME, Wick G. (1996) Endothelial cell apoptosis is a primary pathogenetic event underlying skin lesions in avian and human scleroderma. J. Clin. Invest. 98: 785792.

14. Haynes DC, Gershwin ME. (1984) Diversity of autoantibodies in avian scleroderma. An inherited fibrotic disease of White Leghorn chickens. J. Clin. Invest. 73: 1557-1568.

15. Gruschwitz MS, Shoenfeld Y, Krupp M, et al. (1993) Antinuclear antibody profile in UCD line 200 chickens: A model for progressive systemic sclerosis. Int. Arch. Allergy Immunol. 100: 307-313.

16. LeRoy EC. (1981) The connective tissue in scleroderma. Coll. Rel. Res. 1: 301-308.
17. LeRoy EC. (1977) Collagen synthesis by scleroderma fibroblasts in culture. Arthritis Rheum. 20: 902-903.

18. Duncan MR, Wilson TJ, Van De Water J, et al. (1992) Cultured fibroblasts in avian scleroderma, an autoimmune fibrotic disease, display an activated phenotype. $J$. $A u$ toimmun. 5: 603-615.

19. Kahari VM, Sandberg M, Kalimo H, Vuorio T, Vuorio E. (1988) Identification of fibroblasts responsible for increased collagen production in localized scleroderma by in situ hybridization. J. Invest. Dermatol. 90: 664-670.

20. Abplanalp H, Gershwin ME, Johnston E, Reid J. (1990) Genetic control of avian scleroderma. Immunogenetics 31: 291-295.

21. Mäkelä JK, Vuorio E. (1986) Type I collagen messenger RNA levels in experimental granulation tissue and silicosis rats. Med. Biol. 64: 15-22.

22. Vuorio E, Sandell L, Kravis D, et al. (1982) Construction and partial characterization of two recombinant cDNA clones for procollagen from chicken cartilage. Nucl. Acids. Res. 10: 1175-1191.

23. Yamada $Y$, Kühn $K$, de Crombrugghe $B$. (1983) A conserved nucleotide sequence, coding for a segment of the C-propeptide, is found at the same location in different collagen genes. Nucl. Acids. Res. 11: 2733-2744.

24. Bonaldo P, Russo V, Bucciotti F, Bressan GM, Colombatti A. (1989) Alpha 1 chain of chick type VI collagen. J. Biol. Chem. 264: 5575-5580.

25. Trueb B, Schaeren-Wiemers N, Schreier T, Winterhalter KH. (1989) Molecular cloning of chicken type VI collagen. J. Biol. Chem. 264: 136-140.

26. Bonaldo P, Russo V, Bucciotti F, Doliana R, Colombatti A. (1990) Structural and functional features of the alpha 3 chain indicate a bridging role for chicken collagen VI in connective tissues. Biochemistry 29: 1245-1254.

27. Dugaiczyk A, Haron JA, Stone EM, Dennison OE, Rothblum KN, Schwartz RJ. (1983) Cloning and sequencing of a deoxyribonucleic acid copy of glyceraldehyde-3-phosphate dehydrogenase messenger ribonucleic acid isolated from chicken muscle. Biochemistry 22: 1605-1613.

28. Mays PK, Bishop JE, Laurent GJ. (1988) Age-related changes in the proportion of types I and III collagen. Mech. Ageing Dev. 45: 203-212.

29. Peltonen J, Kahari L, Uitto J, Jimenez SA. 
(1990) Increased expression of type VI collagen genes in systemic sclerosis. Arthritis Rheum. 33: 1829-1835.

30. Heckmann M, Aumailley M, Hatamochi A, Chu ML, Timpl R, Krieg T. (1989) Downregulation of alpha 3 (VI) chain expression by gamma-interferon decreases synthesis and deposition of collagen type VI. Eur. J. Biochem. 182: 719-726.

31. Koller E, Trueb B. (1992) Characterization of the chicken alpha $1(\mathrm{VI})$ collagen promoter. Eur. J. Biochem. 208: 769-774.

32. Botstein GR, Sherer GK, LeRoy EC. (1982) Fibroblast selection in scleroderma. An alternative model of fibrosis. Arthritis Rheum. 25: 189-195.

33. Kahari VM. (1993) Activation of dermal connective tissue in scleroderma. Ann. Med. 25: $511-518$.

34. Scharffetter K, Lankat Buttgereit B, Krieg T. (1988) Localization of collagen mRNA in normal and scleroderma skin by in-situ hybridization. Eur. J. Clin. Invest. 18: 9-17.

35. Perlish JS, Lemlich G, Fleischmajer R. (1988) Identification of collagen fibrils in scleroderma skin. J. Invest. Dermatol. 90: 48-54.

36. Kahari VM, Heino J, Vuorio E. (1987) Interleukin-1 increases collagen production and mRNA levels in cultured skin fibroblasts. Biochim. Biophys. Acta 929: 142-147.

37. Myers RM, Larin Z, Maniatis T. (1985) Detection of single base substitutions by ribonuclease cleavage at mismatches in RNA: DNA duplexes. Science 230: 1242-1246.

Communicated by N.A. Mitchison. Accepted July 30, 1997. 